\title{
Sequential Congruency Effects of Reverse Stroop Interference On Event-Related Potential Components For Go- and Nogo-Stimuli
}

Kota Suzuki ( $\sim$ kt.suzuki@hotmail.co.jp )

Shitennoji University

\section{Research Article}

Keywords: reverse Stroop interference, Go/Nogo task, N1, N2, P3

Posted Date: February 1st, 2021

DOl: https://doi.org/10.21203/rs.3.rs-156555/v1

License: (c) (i) This work is licensed under a Creative Commons Attribution 4.0 International License.

Read Full License

Version of Record: A version of this preprint was published at Frontiers in Psychology on July 29th, 2021. See the published version at https://doi.org/10.3389/fpsyg.2021.678647. 


\section{Abstract}

Sequential congruency effects are observed in interference tasks, in which RTs are shorter for congruent stimuli preceded by congruent (cC) than incongruent stimuli (iC), and RTs are longer for incongruent stimuli preceded by congruent (cl) than incongruent stimuli (il). These effects are interpreted as resulting from incongruent stimuli triggering attentional control in the next trial, which reduces cognitive control. The aim of this study was to examine sequential congruency effects on ERP components for Go- and Nogo-stimuli using the hybrid reverse Stroop Go/Nogo task. Results indicated that the Nogo-N1 was reduced by trials preceded by incongruent stimuli compared to congruent ones, suggesting that color processing was inhibited by attentional control. However, there was no reduction in the Go-N1. Moreover, the Nogo-N2 amplitudes were larger for $\mathrm{Cl}$ than il and iC than $\mathrm{cC}$. On the other hand, the Go-N2 was not modulated by sequential modulation effects, which was lower for incongruent stimuli than congruent stimuli. These results indicate that the Nogo-N2 is involved in cognitive control, whereas the Go-N2 is associated with selection processing. Therefore, it was suggested that response inhibition task demands are necessary for modulating the ERP components by sequential congruency effects.

\section{Introduction}

The participants conducting a Go/Nogo task are required to respond to one type of stimuli (i.e., Go stimuli) and withhold responding to another type (i.e., Nogo stimuli). Moreover, Go- and Nogo-stimuli are known to elicit different event-related potential components (ERP). The distribution of the positive ERP component peaking from 300 to $500 \mathrm{~ms}$, i.e., the P3, has been demonstrated at parieto-occipital scalp sites for Go-stimuli (i.e., the Go-P3 or the P3b) ${ }^{1}$. The P3 has been shown at more frontal sites for Nogostimuli (the Nogo-P3 or the P3a) ${ }^{1,2}$. It is well known that rare target stimuli enhance the Go-P3 than frequent stimuli in the oddball task ${ }^{1,3}$. Also, the Go-P3 amplitude is reduced as a function of target probability in the prior sequence ${ }^{4}$. It has been reported that the Go-P3 is associated with the performance of recall tasks ${ }^{5}$. Therefore, the Go-P3 might be related to context updating operations and subsequent memory storage ${ }^{1,3}$. On the other hand, the Nogo-P3 is enhanced by cues inducing a high degree of response preparation ${ }^{6-8}$. Participants with short reaction times (RTs) might require more response inhibition effort than those with long RTs. The Nogo-P3 was larger in participants with short compared to long RTs ${ }^{9}$, suggesting that the Nogo-P3 is related to response inhibition ${ }^{10-12}$.

The front-central negative ERP component peaking from 200 to $350 \mathrm{~ms}$, i.e., N2, is also involved with the Go/Nogo task. The N2 amplitudes are larger for Nogo-stimuli (i.e., the Nogo-N2) than Go-stimuli (i.e., the Go-N2) ${ }^{13}$. However, the difference between the Nogo-N2 and the Go-N2 is not directly associated with differences in response inhibition efforts. There was no difference in the Nogo-N2 between participants with short and long RTs ${ }^{9}$. Donkers and Van Boxtel ${ }^{14}$ administered the Go/Nogo task and the Go/GO tasks, in which responses with maximal force was required for GO-stimuli. Results indicated that the Nogo-N2 and the GO-N2 were enhanced in the low probability condition compared to the equal probability 
condition ${ }^{14}$. These findings suggest that the Nogo-N2 and the Go-N2 are associated with cognitive control preceding motor responses ${ }^{10-12}$.

Previous studies have suggested that the N2 in the Go/Nogo task is related to conflicts. Conflicts are assumed to occur when incompatible response representations are simultaneously activated ${ }^{15,16}$. A conflict in the Go/Nogo task is reflected by an incompatibility between the representation for response execution and the representation for stopping the response ${ }^{8,17}$. The degree of conflict can be manipulated by the probability and the cue in the Go/Nogo task. Previous studies have demonstrated that the $\mathrm{N} 2$ could be modulated by the degree of conflict $8,14,18$. For example, representations for response execution and stopping the response are activated by Go- stimuli after a cue informing a Nogo-stimulus. A high degree of conflict might occur without any response inhibition demands of Go-stimuli after a cue informing a Nogo-stimulus, because no response inhibition is required for Go-stimuli. Go-stimuli after a cue informing a Nogo-stimulus elicited larger N2 amplitudes than Go stimuli after a cue informing a Gostimulus ${ }^{8}$.

Conflicts in interference tasks are also well-studied, including the flanker task, the Stroop task, and the reverse Stroop task ${ }^{15,16}$. The Stroop and the reverse Stroop tasks' stimuli are words expressing a color painted in a congruent or an incongruent color. The participants in the Stroop task ${ }^{19}$ are asked to respond to the color, whereas they are asked to respond to the word's meaning in the reverse Stroop task 20. Typically, longer RTs are observed for incongruent than congruent stimuli, suggesting that the incongruency between the color and the word's meaning causes a conflict. Moreover, sequential congruency effects are observed in the behavioral results of the interference task; RTs are shorter for congruent stimuli preceded by congruent ones (cC) than incongruent ones (iC), and RTs are longer for incongruent stimuli preceded by congruent ones (cl) than incongruent ones (il) ${ }^{21}$. The sequential congruency effects are interpreted as incongruent stimuli triggering the inhibition of irrelevant processing through attentional control in the next trial, which reduces the degree of conflict and effort for cognitive control ${ }^{15,22}$.

The sequential congruency effects on the N2 and the P3 have been reported in previous interference task studies ${ }^{23-25}$. The N2 and the P3 were enhanced by $\mathrm{cl}$ than il in the flanker task ${ }^{23}$. The probability of incongruent stimuli reportedly modulated the $\mathrm{N} 2$ and the $\mathrm{P} 3{ }^{24,25}$. These findings suggested that the N2 was associated with the degree of conflict, consistent with previous Go/Nogo task studies. The P3 was also involved with interference task conflicts, unlike the Go/Nogo task. However, this finding might indicate that a high degree of conflict requires a large response inhibition effort.

Interference tasks used in previous studies required a choice response ${ }^{23-25}$. It is known that Go- and Nogo-stimuli differently influence ERP components $1,3,13$ and possible the sequential congruency effects of interference tasks are different for ERP components for Go- and Nogo-stimuli. A previous study 26 examined the effects of flanker interference on ERP components for Go-stimuli, Nogo-stimuli, and choice response stimuli and indicated that the N2 and the P3 were enhanced by incongruent relative to 
congruent stimuli ${ }^{26}$. However, little is known about interference effects and sequential congruency effects of other tasks on ERP components for Go- and Nogo-stimuli.

This study's main aim was to examine sequential congruency effects on ERP components for Go- and Nogo-stimuli. Therefore, the hybrid reverse Stroop Go/Nogo task was developed (Figure 1). Additionally, this study also examined the modulation of the $\mathrm{N} 1$ by the sequential congruency effect. A previous study of the flanker task demonstrated that the $\mathrm{N} 1$ was reduced by trials preceded by incongruent stimuli relative to congruent stimuli, which was explained as resulting from attentional control ${ }^{27}$. Therefore, in the current experiment, it was assumed that the Go-N1 and the Nogo-N1 were modulated by the previous trial congruency.

\section{Method}

\section{Participants}

Undergraduate and graduate students $(\mathrm{N}=21)$ participated in this study. Two participants' data were excluded from the analyses because their data had excessive electroencephalogram (EEG) artifacts. The data of 19 participants was used (sex:10 males, 9 females, handedness: 16 right-handers, 3 left-handers). Their ages ranged from 18 to 23 years ( $19.63 \pm 1.16$ years). All participants gave their written informed consent before the experiment. The experimental procedure was approved by the ethics committee of Shitennoji University (2019-53), and in accordance with the Declaration of Helsinki.

\section{Task}

The experiment was controlled using Psychtoolbox Version 3 and GNU Octave. The stimuli in the hybrid reverse Stroop Go/Nogo task were two Kanji characters (width $=2.15^{\circ}$, height $=2.16^{\circ}$ ), i.e., " $\nabla^{\prime \prime}$ meaning "red," and " $\square$ " meaning "blue." The stimuli were painted in congruent or incongruent colors (Figure 1). Participants were asked to press a button using their dominant hand's thumb in response to one of the two characters (i.e, Go-stimulus) and stop responding to the other character (i.e., Nogo-stimulus). The character, " $\nabla$ " was the Go-stimulus for ten participants, whereas " $\nabla$ " was the Go-stimulus for the others. The conditions of the Go/Nogo and the present trial congruency were set to equal frequencies. The trials were classified into eight conditions based on the Go/Nogo, the present trial congruency, and the previous trial congruency. The portion of trials ranged from $12.22 \%$ to $13.02 \%$ (Go cC: $12.70 \%$, iC: $12.70 \%$, cC: $12.70 \%$, cC: $12.70 \%$; Nogo cC: $12.86 \%$, iC: $12.38 \%$, il: $13.02 \%$, cl: $12.22 \%)$.

Color tasks were conducted before the reverse Stroop task block to increase attendance to colors and enhance the reverse Stroop interference-effect. Stimuli were circles (width $=2.15^{\circ}$, height $=2.15^{\circ}$ ) painted in red or blue (Figure 1). Participants were asked to press a button using their dominant hand's thumb in response to one color and stop responding to the other color. Go- and Nogo-stimuli were equally presented. 
The stimuli in both tasks were presented for $100 \mathrm{~ms}$, and the stimulus onset asynchronies were randomly set between $1200 \mathrm{~ms}$ and $1500 \mathrm{~ms}$ range (step $=100 \mathrm{~ms}$ ). A block consisted of 64 trials in the hybrid reverse Stroop Go/Nogo task, whereas it consisted of 16 trials in the color task. Participants performed ten sets composed of one block of the color task and one block of the reverse Stroop task after conducting one set as a practice session.

\section{EEG recordings and analyses}

EEGs were recorded from 31 scalp locations (i.e., Fp1, Fp2, F7, F3, Fz, F4, F8, T7, C3, Cz, C4, T8, FC3, FCz, FC4, P7, P3, Pz, P4, P8, P08, P03, POz, P04, P07, CP3, CPz, CP4, 01, Oz, 02) using BIO-NVX 36 (Medical Computer Systems). The reference and ground channels were located at the nose tip and AFz, respectively. The sampling rate was $1000 \mathrm{~Hz}$, with impedances maintained under $10 \mathrm{k} \Omega$.

EEGs and ERPs were analyzed using MATLAB R2019a (Mathwork inc.) and EEGLAB v2019.0 ${ }^{34}$. Offline EEGs were re-referenced to the averages for all the channels and were bandpass filtered from 0.1 to 50 $\mathrm{Hz}$. Epochs were extracted from -100 to 1000 ms triggered by stimulus onset, and means of durations from -100 to 0 ms were used as the baseline. Artifacts related to eye movements and muscle activities were excluded by pca and bsscca functions of the automatic artifact removal toolbox ${ }^{35}$. Epochs with \pm $50 \mu \mathrm{V}$ were automatically excluded, and epochs contaminating artifacts (e.g., eye movements) were further excluded by a visual inspection. ERPs were computed for eight conditions ( $\mathrm{cC}$, iC, $\mathrm{cl}$, and il for Goand Nogo-stimuli).

Go-N1 and Nogo-N1 amplitudes were calculated as means from 150 to $200 \mathrm{~ms}$ at P7 and P8. Go-N2 and Nogo-N2 amplitudes were calculated as the means from 220 to $320 \mathrm{~ms}$ at Fz, FCz, and Cz. Go-P3 amplitudes were calculated as means of the two ranges from 300 to 400 and from 400 to $500 \mathrm{~ms}$ at Pz and POz. Nogo-P3 amplitudes were calculated as the means of the two ranges from 350 to $425 \mathrm{~ms}$ and from 425 to $500 \mathrm{~ms}$ at $\mathrm{FCz}, \mathrm{Cz}$, and $\mathrm{Pz}$.

\section{Statistical analyses}

Repeated measures ANOVAs with the present trial congruency and the previous trial congruency were conducted on correct RT and commission error rates. Repeated measures ANOVAs with channels, the present trial congruency, and the previous trial congruency were conducted on Go-N2, Go-P3s, Nogo-N2, and Nogo-P3s amplitudes. Simple effect analyses were performed if the interaction between two variables was significant. Also, paired t-tests were used to examine differences in Nogo-N2 amplitudes between $\mathrm{iC}$ and $\mathrm{cl}$ and between il and $\mathrm{CC}$. Repeated measures ANOVAs were performed for the present trial congruency and the previous trial congruency in each channel if the interaction among the three variables were significant for ERP amplitudes. Bonferroni tests were used for post-hoc tests.

\section{Results}

\section{Behavioral results}


Figure 2 shows correct RTs for Go-stimuli, and commission error rates for Nogo-stimuli in each condition. Omission error rates for Go-stimuli were nearly $0 \%$ in each condition (mean \pm standard deviation of age, cC: $0.20 \pm 0.49 \%$, iC: $0.34 \pm 0.58 \%$, cl: $0.47 \pm 0.96 \%$, il: $0.20 \pm 0.47 \%)$.

A repeated measures analysis of variance (ANOVA) on correct RTs showed a significant main effect of the present trial congruency $\left(F(1,18)=93.24, p<.001, \eta_{p}^{2}=.84\right)$ and a significant interaction between the present and previous trial congruencies $\left(F(1,18)=71.88, p<.001, \eta_{p}{ }^{2}=.80\right)$. However, there was no significant main effect of the previous trial congruency $\left(F(1,18)=0.37, p=.55, \eta_{p}{ }^{2}=.02\right)$. A simple effect analysis showed a significant main effect of the present trial congruency on trials preceded by congruent stimuli $\left(F(1,18)=135.10, p<.001, \eta_{p}^{2}=.88\right)$, on trials preceded by incongruent stimuli $(F(1,18)=21.72, p$ $\left.<.001, \eta_{p}^{2}=.55\right)$, previous trial congruency on congruent stimuli in the present trial $(F(1,18)=34.15, p<$ $\left..001, \eta_{p}{ }^{2}=.65\right)$ and incongruent stimuli in the present trial $\left(F(1,18)=29.73, p<.001, \eta_{p}{ }^{2}=.62\right)$. These results indicated that the correct RT was the longest for $\mathrm{cl}$, longer for il than $\mathrm{iC}$, and was the shortest for cC (Figure 2).

The repeated measures ANOVA on commission error rates showed a significant main effect of the present trial congruency $\left(F(1,18)=21.92, p<.001, \eta_{p}^{2}=.55\right)$, and a significant interaction between present and previous trial congruencies $\left(F(1,18)=13.73, p<.01, \eta_{p}^{2}=.43\right)$. However, there was no significant main effect of the previous trial congruency $\left(F(1,18)=4.00, p=.06, \eta_{p}^{2}=.18\right)$. A simple effect analysis showed a significant main effects of the present trial congruency on trials preceded by congruent stimuli $\left(F(1,18)=23.43, p<.001, \eta_{p}^{2}=.57\right)$, trials preceded by incongruent stimuli $(F(1,18)=$ $\left.6.73, p<.05, \eta_{p}^{2}=.27\right)$, and the previous trial congruency on incongruent stimuli in the present trial $\left(F(1,18)=8.59, p<.01, \eta_{p}^{2}=.32\right)$. However, there was no significant main effect of the previous trial congruency on congruent stimuli in the present trial $\left(F(1,18)=2.23, p=.15, \eta_{p}^{2}=.11\right)$. These results indicated that commission error rates were the largest for $\mathrm{Cl}$, and larger for $\mathrm{cl}$ than iC or CC (Figure 2).

\section{ERP components for Go-stimuli}

Figure 3 shows the grand average ERP waveforms and the topographies of ERP components for Go stimuli, and Table 1 shows the means of the ERP amplitudes for Go stimuli. The repeated measures ANOVA on Go-N1 amplitudes indicated no significant main effects or interactions (Table 2).

The repeated measures ANOVA on Go-N2 amplitudes revealed a significant interaction between channels and the present trial congruency (Table 2). A simple effect analysis showed a significant effect of channels on congruent stimuli in the present trial $\left(F(2,36)=5.27, p<.01, \eta_{p}^{2}=.23\right)$, where Go-N2 amplitudes were significantly larger at FCz than Fz $(p<.05)$. Also, there were significant effects of the present trial congruency at $\mathrm{FCz}\left(F(1,18)=7.18, p<.05, \eta_{p}^{2}=.28\right)$ and $\mathrm{Cz}\left(F(1,18)=7.04, p<.05, \eta_{p}^{2}=\right.$ .28), which indicated that Go-N2 amplitudes were significantly larger for congruent stimuli than for incongruent ones in the present trial at FCz than Fz. There was neither a significant effects of channels 
on incongruent stimuli in the present trial $\left(F(1,18)=1.75, p=.19, \eta_{p}{ }^{2}=.09\right)$, nor a significant effect of the present trial congruency on $\mathrm{Fz}\left(F(1,18)=0.80, p=.38, \eta_{p}^{2}=.04\right)$.

There were neither a significant effect nor any significant interactions in the repeated measures ANOVA on Go-P3 amplitudes from 300 to 400 ms, whereas the repeated measures ANOVA on Go-P3 amplitudes from 400 to $500 \mathrm{~ms}$ indicated a significant interaction between present and previous trial congruencies (Table 2). A simple effect analysis showed a significant main effect of the present trial congruency on trials preceded by congruent stimuli $\left(F(1,18)=18.14, p<.001, \eta_{p}{ }^{2}=.50\right)$ and a significant main effect of the previous trial congruency on incongruent stimuli in the present trial $\left(F(1,18)=9.75, p<.01, \eta_{p}^{2}=.35\right)$. There were neither a significant main effect of the present trial congruency on trials preceded by incongruent stimuli $\left(F(1,18)=0.17, p=.68, \eta_{p}^{2}=.01\right)$ nor a significant main effect of the previous trial congruency on incongruent stimuli in the present trial $\left(F(1,18)=0.38, p=.54, \eta_{p}^{2}=.02\right)$. These results indicated that Go-P3 amplitudes from 400 to $500 \mathrm{~ms}$ were the largest for $\mathrm{cl}$ (Figure 4).

\section{ERP components for Nogo-stimuli}

Figure 5 shows the grand average ERP waveforms and the topographies of ERP components for Nogo stimuli, and Table 3 shows the means of each ERP component for Nogo stimuli. The repeated measures ANOVA on the Nogo-N1 amplitudes revealed a significant main effect of the previous trial congruency (Table 4), which indicated that Nogo-N1 amplitudes were significantly smaller in trials preceded by incongruent stimuli than congruent ones.

A repeated measures ANOVA on Nogo-N2 amplitudes (Table 4) indicated a significant interaction among channels, the present trial congruency, and the previous trial congruency. The ANOVAs revealed a significant interaction between present and previous trial congruencies at $\mathrm{FCz}(F(1,18)=11.36, p<.01$, $\left.\eta_{p}^{2}=.39\right)$ and $\mathrm{Cz}\left(F(1,18)=26.62, p<.001, \eta_{p}^{2}=.60\right)$, whereas the interaction was not significant at $\mathrm{Fz}$ $\left(F(1,18)=2.28, p=.15, \eta_{p}^{2}=.11\right)$. A simple effect analysis on Nogo-N2 amplitudes at FCz showed significant main effects of the present trial congruency on trials preceded by congruent stimuli $(F(1,18)=$ $\left.6.11, p<.05, \eta_{p}^{2}=.25\right)$ and the previous trial congruency on congruent stimuli in the present trial $(F(1,18)$ $=10.68, p<.01, \eta_{p}{ }^{2}=.37$ ), whereas there were neither significant main effects of the present trial congruency on trials preceded by incongruent stimuli $\left(F(1,18)=1.08, p=.31, \eta_{p}^{2}=.06\right)$ nor of the previous trial congruency on incongruent stimuli in the present trial $\left(F(1,18)=2.00, p=.17, \eta_{p}^{2}=.10\right)$. The simple effect analysis of Nogo-N2 amplitudes at Cz showed a significant main effect of the present trial congruency on trials preceded by congruent stimuli $\left(F(1,18)=28.16, p<.001, \eta_{p}^{2}=.61\right)$, a significant main effect of the previous trial congruency on congruent stimuli $\left(F(1,18)=15.31, p<.01, \eta_{p}^{2}=.46\right)$ and incongruent stimuli in the present trial $\left(F(1,18)=7.80, p<.05, \eta_{p}{ }^{2}=.30\right)$, whereas there was no significant main effect of the present trial congruency on trials preceded by incongruent stimuli $(F(1,18)=0.30, p=$ $\left..59, \eta_{p}^{2}=.02\right)$. In addition, paired t-tests confirmed that $\mathrm{N} 2$ amplitudes at $\mathrm{Cz}$ were larger for il than $\mathrm{cC}$ $(t(1,18)=3.29, p<.01)$ and $\mathrm{cl}$ than $\mathrm{iC}(t(1,18)=2.91, p<.01)$. These results indicated that Nogo-N2 
amplitudes were the largest for $\mathrm{cl}$, and the smallest for $\mathrm{cC}$. Moreover, there was no difference between Nogo-N2 amplitudes for il and iC trials (Figure 6).

The repeated measures ANOVA on Nogo P3 amplitudes from 350 to 425 showed significant main effects of channels and present and previous trial congruencies (Table 4). There was a significant interaction among channels, the present trial congruency, and the previous trial congruency. Moreover, there was a significant interaction between present and previous trial congruencies at $\mathrm{Pz}\left(F(1,18)=8.89, p<.01, \eta_{p}^{2}=\right.$ .33), whereas the interactions were not significant at FCz $\left(F(1,18)=0.49, p=.49, \eta_{p}^{2}=.03\right)$ and $\mathrm{Cz}$ $\left(F(1,18)=0.13, p=.72, \eta_{p}^{2}=.01\right)$. Simple effect analysis of Nogo-P3 amplitudes from 350 to 425 at $\mathrm{Pz}$ showed significant main effects of the present trial congruency on trials preceded by congruent stimuli $\left(F(1,18)=11.86, p<.01, \eta_{p}^{2}=.40\right)$ and the previous trial congruency on incongruent stimuli in the present trial $\left(F(1,18)=19.25, p<.001, \eta_{p}^{2}=.52\right)$, whereas there was nether a significant main effect of the present trial congruency on trials preceded by incongruent stimuli $\left(F(1,18)=1.02, p=.33, \eta_{p}^{2}=.05\right)$ nor previous trial congruency on congruent stimuli in the present trial $\left(F(1,18)=0.17, p=.69, \eta_{p}^{2}=.01\right)$. These results indicated that the Nogo-P3 amplitudes from 350 to 425 at Pz were larger for $\mathrm{cl}$ than cC or il.

A repeated measures ANOVA on Nogo-P3 amplitudes from 425 to 500 showed significant main effects of present and previous trial congruencies and the interaction between them. Simple effect analysis indicated significant main effects of the present trial congruency on trials preceded by congruent stimuli $\left(F(1,18)=18.82, p<.001, \eta_{p}^{2}=.51\right)$, trials preceded by incongruent stimuli $\left(F(1,18)=5.14, p<.05, \eta_{p}^{2}=\right.$ $.22)$, and the previous trial congruency on incongruent stimuli in the present trial $(F(1,18)=10.27, p<.01$, $\left.\eta_{p}^{2}=.36\right)$, whereas there were no significant main effects of the previous trial congruency on congruent stimuli in present trials $\left(F(1,18)=0.05, p=.83, \eta_{p}^{2}=.00\right)$. These results indicated that Nogo-P3 amplitudes from 425 to 500 were larger for $\mathrm{cl}$ than il, cl than $\mathrm{cC}$, and il than iC (Figure 6).

\section{Discussion}

This study examined sequential congruency effects of reverse Stroop interference on ERP components for Go- and Nogo-stimuli using the hybrid reverse Stroop Go/Nogo task. Results indicated that RTs in this task were longer for $\mathrm{iC}$ than $\mathrm{cC}$, and $\mathrm{cl}$ than $\mathrm{il}$, and commission error rates were higher for $\mathrm{cl}$ than il. These behavioral results confirmed sequential congruency effects in the hybrid reverse Stroop Go/Nogo task.

These results indicated that Nogo-N1 amplitudes were smaller in trials preceded by incongruent stimuli than congruent stimuli. A previous study using the flanker task also demonstrated identical results, suggesting the inhibition of processing for the surrounding irrelevant non-targets ${ }^{27}$. Moreover, N1 amplitudes were larger in fluent Kanji readers compared to naïve Kanji readers ${ }^{28}$. Enhancement of $\mathrm{N} 1$ has been reported for color-discrimination tasks compared to simple reaction tasks ${ }^{29,30}$ suggesting that attending to Kanji characters and the color is associated with the N1. Therefore, the current results suggest that inhibition of color processing was associated with the reduction of the Nogo-N1. 
Contrary to the Nogo-N1, the Go-N1 was not modulated by the previous trial congruency. N1 amplitudes were larger in the discrimination task than in a simple reaction task ${ }^{29}$, suggesting that task demands influenced N1. The color was associated with stopping a response; however, omission error rates were approximately $0 \%$ for incongruent Go-stimuli, meaning that Go-stimuli might not need attentional control. Hence, it is suggested that the lack of task demands in response inhibition might be associated with low attentional control needs, which might eliminate the modulation of the Go-N1.

The Nogo-N1 was modulated by the previous trial congruency, which was not the case in the modulation of the Go-N1. Color processing interferes with word processing in the reverse Stroop task, and as a result, attentional control engages after inputting a stimulus. Interference in the flanker task occurs through the incongruence between the central target and the surroundings non-targets. Therefore, processing surrounding non-target locations can be proactively inhibited before an input, which might influence the $\mathrm{N} 1$ amplitude ${ }^{27}$. As a result, the modulation of the Go-N1 may be observed in flanker interference. It is expected that future studies would examine differences in effects on ERP components for Go- and Nogostimuli based on interference types.

The Nogo-N2 amplitudes at Cz were larger for $\mathrm{cl}$ than il. The Nogo-N2 is associated with cognitive control preceding motor responses, specifically conflict processes $8,14,18,26$. The Nogo-N2 was modulated by sequential congruency effects, consistent with previous studies on interference tasks ${ }^{23-25}$. However, the degree of conflict between iC and $\mathrm{CC}$ might not be different, whereas the Nogo-N2 amplitudes were larger for iC than $\mathrm{CC}$. In addition, the degree of conflict was larger for il than $\mathrm{iC}$, whereas there was no difference in the N2 between il and iC. These findings suggested that N2 was not directly associated with the degree of conflict.

Previous studies have suggested that subcomponents of N2 reflect mismatches with the mental template 31. The modulation of the Nogo-N2 was possibly associated with a mismatch with the mental template based on the previous trial congruency. However, the $\mathrm{iC}$ and $\mathrm{cl}$ mismatch occurred for both the Go- and the Nogo-stimuli without the modulation of the Go-N2. Therefore, it was considered that task demands of response inhibition were necessary to modulate the $\mathrm{N} 2$ by sequential congruency effects. This study also showed that Nogo-N2 amplitudes were larger for $\mathrm{cl}$ than iC, suggesting that a high degree of effort for cognitive control increased Nogo-N2 amplitudes. Therefore, the Nogo-N2 might be involved in cognitive control, even though it was not directly associated with the degree of conflict.

The Go-N2 decreased for incongruent than congruent stimuli in the present trial. It has been reported that the Go-N2 and the Nogo-N2 decrease because of task complexity ${ }^{32}$. The N2b is a subcomponent of the $\mathrm{N} 2$ and reflects selection processing ${ }^{33}$. The N2b amplitudes were larger for target stimuli than non-target stimuli and were enhanced by relevant color non-target stimuli compared to irrelevant ones ${ }^{33}$. The cognitive control effort was possibly reduced by the lack of response inhibition task demands or Gostimuli, suggesting that the Go-N2 was more strongly associated with selection processing (i.e., N2b) than cognitive control. These findings suggest that the incongruent stimuli blurred target-related features and decreased Go-N2 amplitudes. 
Nogo-P3 amplitudes from 425 to 500 ms were the largest for $\mathrm{cl}$ and were larger for il than $\mathrm{cC}$ or iC. It was suggested that the Nogo-P3 is related to response inhibition ${ }^{10-12}$. Previous studies have demonstrated that the Nogo-P3 is modulated by sequential congruency effects ${ }^{23-25}$. It is assumed that incongruent stimuli resulted in stronger response execution than congruent stimuli, which increased for $\mathrm{cl}$ relative to il. Thus, the response inhibition effort might be stronger for $\mathrm{cl}$ than il. It is suggested that the Nogo-P3 results of this study are associated with changes in the response inhibition effort due to the sequential congruency effect.

The largest Go-P3 amplitudes were observed for $\mathrm{cl}$, whereas there were no differences in $\mathrm{CC}$, iC, or $\mathrm{cl}$ amplitudes. The Go-P3 is related to context updating operations and subsequent memory storage ${ }^{1,3}$. The results of Nogo-N1 indicated that incongruent stimuli triggered attentional control on the next trial; therefore, the context change from congruent to incongruent stimuli is crucial. On the other hand, context changes from incongruent to congruent stimuli were considered less important because congruent stimuli need not engage attentional control. Therefore, the enhancement of the Go-P3 in cl might involve a change in attentional control in the next trial.

This study examined sequential congruency effects on ERP components for Go-stimuli and Nogo-stimuli, using the hybrid reverse Stroop Go/Nogo task. The sequential congruency effects were interpreted as attentional control inhibiting color processing in trials preceded by incongruent stimuli, which reduced efforts for cognitive control and response inhibition ${ }^{15}$. The Nogo-N1 was reduced by trials preceded by incongruent stimuli relative to congruent ones, suggesting the inhibition of color processing by incongruent stimuli on previous trials. Nogo-N2 amplitudes were larger for $\mathrm{cl}$ than il and iC than $\mathrm{cC}$, which might be related to cognitive control. Nogo-P3 amplitudes were the largest for $\mathrm{cl}$ and were larger for incongruent stimuli than congruent stimuli. Therefore, the Nogo-P3 increased according to changes in the response inhibition effort caused by sequential congruency effects. On the other hand, the Go-N1 was not modulated by the previous trial congruency, and the Go-N2 was reduced on trials preceded by incompatible stimuli relative to congruent ones. These findings suggest that response inhibition task demand was necessary for the modulation of the ERP components by sequential congruency effects.

\section{Declarations}

\section{Contributions}

KS contributed to the study design, data collection, interpreting the data, writing the manuscript.

\section{Funding}

This work was supported in part by a Grant-in-Aid for Scientific Research (C) (grant number 19K03304) from the Ministry of Education, Science and Culture of Japan.

\section{Competing interest}


The author had no conflicts of interest to report.

\section{Data availability}

The data that support the findings of this study are available on request from the author, and approval by the ethics committee of Shitennoji university. The data are not publicly available because no informed consent was given by the participants for open data sharing.

\section{References}

1. Polich, J. Neuropsychology of P300 in The Oxford Handbook of Event-Related Potential Components (eds S Luck \& E Kaooenman) 159-188 (Oxford University Press, 2012).

2. Fallgatter, A. J. \& Strik, W. K. The NoGo-anteriorization as a neurophysiological standard-index for cognitive response control. Int. J. Psychophysiol. 32, 233-238 (1999).

3. Polich, J. Updating P300: an integrative theory of P3a and P3b. Clin. Neurophysiol. 118, 2128-2148 (2007).

4. Duncan-Johnson, C. C. \& Donchin, E. On quantifying surprise: The variation of event-related potentials with subjective probability. Psychophysiology 14, 456-467 (1977).

5. Karis, D., Fabiani, M. \& Donchin, E. "P300" and memory: Individual differences in the von Restorff effect. Cogn. Psychol. 16, 177-216 (1984).

6. Smith, J. L., Johnstone, S. J. \& Barry, R. J. Response priming in the Go/NoGo task: the N2 reflects neither inhibition nor conflict. Clin. Neurophysiol. 118, 343-355 (2007).

7. Bruin, K., Wijers, A. \& Van Staveren, A. Response priming in a go/nogo task: do we have to explain the go/nogo N2 effect in terms of response activation instead of inhibition? Clin. Neurophysiol. 112, 1660-1671 (2001).

8. Randall, W. M. \& Smith, J. L. Conflict and inhibition in the cued-Go/NoGo task. Clin. Neurophysiol. $122,2400-2407$ (2011).

9. Smith, J. L., Johnstone, S. J. \& Barry, R. J. Effects of pre-stimulus processing on subsequent events in a warned Go/NoGo paradigm: response preparation, execution and inhibition. Int. J. Psychophysiol 61, 121-133 (2006).

10. Suzuki, K. et al. Reduced Nogo-P3 in adults with developmental coordination disorder (DCD). Int. J. Psychophysiol 153, 37-44 (2020).

11. Gajewski, P. D. \& Falkenstein, M. Effects of task complexity on ERP components in Go/Nogo tasks. Int. J. Psychophysio/ 87, 273-278 (2013).

12. Huster, R. J., Enriquez-Geppert, S., Lavallee, C. F., Falkenstein, M. \& Herrmann, C. S. Electroencephalography of response inhibition tasks: functional networks and cognitive contributions. Int. J. Psychophysiol. 87, 217-233 (2013).

13. Pfefferbaum, A., Ford, J. M., Weller, B. J. \& Kopell, B. S. ERPs to response production and inhibition. Electroencephalogr. Clin. Neurophysiol. 60, 423-434 (1985). 
14. Donkers, F. C. \& Van Boxtel, G. J. The N2 in go/no-go tasks reflects conflict monitoring not response inhibition. Brain Cogn. 56, 165-176 (2004).

15. Botvinick, M. M., Braver, T. S., Barch, D. M., Carter, C. S. \& Cohen, J. D. Conflict monitoring and cognitive control. Psychological review 108, 624 (2001).

16. Yeung, N., Botvinick, M. M. \& Cohen, J. D. The neural basis of error detection: conflict monitoring and the error-related negativity. Psychol. Rev. 111, 931 (2004).

17. Stahl, J. \& Gibbons, H. Dynamics of response-conflict monitoring and individual differences in response control and behavioral control: an electrophysiological investigation using a stop-signal task. Clin. Neurophysiol. 118, 581-596 (2007).

18. Smith, J. L., Smith, E. A., Provost, A. L. \& Heathcote, A. Sequence effects support the conflict theory of N2 and P3 in the Go/NoGo task. Int. J. Psychophysiol. 75, 217-226 (2010).

19. Stroop, J. R. Studies of interference in serial verbal reactions. J. Exp. Psychol. 18, 643 (1935).

20. Flowers, J. H. "Sensory" interference in a word-color matching task. Percept. Psychophys. 18, 37-43 (1975).

21. Gratton, G., Coles, M. G. \& Donchin, E. Optimizing the use of information: strategic control of activation of responses. J. Exp. Psychol. Gen. 121, 480 (1992).

22. Kerns, J. G. et al. Anterior cingulate conflict monitoring and adjustments in control. Science $\mathbf{3 0 3}$, 1023-1026 (2004).

23. Larson, M. J. et al. Cognitive control adjustments in healthy older and younger adults: Conflict adaptation, the error-related negativity (ERN), and evidence of generalized decline with age. Biol. Psychol. 115, 50-63 (2016).

24. Panadero, A., Castellanos, M. \& Tudela, P. Unconscious context-specific proportion congruency effect in a stroop-like task. Conscious. Cogn. 31, 35-45 (2015).

25. Jiang, J., van Gaal, S., Bailey, K., Chen, A. \& Zhang, Q. Electrophysiological correlates of block-wise strategic adaptations to consciously and unconsciously triggered conflict. Neuropsychologia 51, 2791-2798 (2013).

26. Groom, M. J. \& Cragg, L. Differential modulation of the N2 and P3 event-related potentials by response conflict and inhibition. Brain Cogn. 97, 1-9 (2015).

27. Suzuki, K. \& Shinoda, H. Transition from reactive control to proactive control across conflict adaptation: An sLORETA study. Brain Cogn. 100, 7-14 (2015).

28. Niermeyer, M. A., Miller, E., Tamaoki, Y., Wiggins, E. \& Stevens, C. Single and compound logographic Kanji words elicit distinct early neurophysiological responses: ERP evidence from fluent and naïve Kanji readers. J. Neurolinguistics 47, 91-104 (2018).

29. Vogel, E. K. \& Luck, S. J. The visual N1 component as an index of a discrimination process. Psychophysiology 37, 190-203 (2000).

30. Hopf, J.-M., Vogel, E., Woodman, G., Heinze, H.-J. \& Luck, S. J. Localizing visual discrimination processes in time and space. J. Neurophysiol. 88, 2088-2095 (2002). 
31. Folstein, J. R. \& Van Petten, C. Influence of cognitive control and mismatch on the N2 component of the ERP: a review. Psychophysiology 45, 152-170 (2008).

32. Mussini, E. et al. The Role of Task Complexity on Frontal Event-related Potentials and Evidence in Favour of the Epiphenomenal Interpretation of the Go/No-Go N2 Effect. Neuroscience 449, 1-8 (2020).

33. Smid, H. G., Jakob, A. \& Heinze, H. J. An event-related brain potential study of visual selective attention to conjunctions of color and shape. Psychophysiology 36, 264-279 (1999).

34. Delorme, A. \& Makeig, S. EEGLAB: an open source toolbox for analysis of single-trial EEG dynamics including independent component analysis. J. Neurosci. Methods 134, 9-21 (2004).

35. Gómez-Herrero, G. Automatic artifact removal (AAR) toolbox v1. 3 (Release 09.12. 2007) for MATLAB. http://germangh.github.io/pubs/aardoc07.pdf (2007).

\section{Tables}

Table 1. Means (standard deviations) of event related potential amplitudes for Go-stimuli 


\begin{tabular}{|c|c|c|c|c|c|c|}
\hline & & $\mathrm{cC}$ & $\mathrm{iC}$ & $\mathrm{cl}$ & il & Main results $(a=.05)$ \\
\hline Go-N1 & P7 & -0.74 & -0.69 & -0.50 & -0.68 & \\
\hline \multirow[t]{3}{*}{$(150$ - $200 \mathrm{~ms})$} & & $(1.80)$ & $(1.55)$ & $(1.73)$ & $(1.82)$ & \\
\hline & P8 & -0.38 & -0.29 & -0.59 & -0.55 & \\
\hline & & $(1.02)$ & $(0.93)$ & (1.09) & (1.11) & \\
\hline Go-N2 & $\mathrm{Fz}$ & -0.17 & -0.16 & -0.07 & -0.11 & $\mathrm{FCz}>\mathrm{Fz}$ at $\mathrm{C}$ \\
\hline \multirow[t]{5}{*}{ (220 - $320 \mathrm{~ms})$} & & $(0.76)$ & $(0.81)$ & $(0.71)$ & $(0.91)$ & $\mathrm{C}>\mathrm{I}$ at $\mathrm{FCz}$ and $\mathrm{Cz}$ \\
\hline & $\mathrm{FCz}$ & -0.75 & -0.75 & -0.36 & -0.53 & \\
\hline & & $(0.86)$ & $(0.90)$ & $(0.98)$ & $(0.97)$ & \\
\hline & $\mathrm{Cz}$ & -0.47 & -0.53 & -0.07 & -0.36 & \\
\hline & & $(0.85)$ & $(0.89)$ & $(1.10)$ & $(0.82)$ & \\
\hline Go-P3 & $\mathrm{Pz}$ & 1.48 & 1.41 & 1.53 & 1.43 & \\
\hline \multirow[t]{3}{*}{$(300-400 \mathrm{~ms})$} & & $(1.35)$ & $(1.41)$ & $(1.39)$ & $(1.26)$ & \\
\hline & $\mathrm{POz}$ & 1.36 & 1.23 & 1.41 & 1.31 & \\
\hline & & $(0.88)$ & $(0.82)$ & $(0.84)$ & $(0.91)$ & \\
\hline Go-P3 & $\mathrm{Pz}$ & 0.97 & 1.06 & 1.51 & 1.06 & $\mathrm{cl}>\mathrm{cC}$, iC and il \\
\hline \multirow[t]{3}{*}{ (400 - $500 \mathrm{~ms})$} & & $(1.23)$ & $(1.32)$ & $(1.40)$ & $(1.25)$ & \\
\hline & $\mathrm{POz}$ & 0.87 & 0.90 & 1.38 & 0.98 & \\
\hline & & $(0.77)$ & $(0.65)$ & $(0.84)$ & $(0.69)$ & \\
\hline
\end{tabular}

Note. cC: congruent (the previous trial) $\rightarrow$ Congruent (the present trial), iC: incongruent $\rightarrow$ Congruent, cl: congruent $\rightarrow$ Incongruent, il: incongruent $\rightarrow$ Incongruent.

Table 2. Analyses of variance results of event related potential components for Go-stimuli 


\begin{tabular}{|c|c|c|}
\hline Components & Variable & Statistical value \\
\hline Go-N1 & A. Channels (P7,P8) & $F(1,18)=0.32, p=.58, \eta_{p}^{2}=.02$ \\
\hline \multirow[t]{6}{*}{$(150-200 \mathrm{~ms})$} & B. Present trial congruency & $F(1,18)=0.34, p=.57, \eta_{p}^{2}=.02$ \\
\hline & C. Previous trial congruency & $F(1,18)=0.00, p=.98, \eta_{p}^{2}=.00$ \\
\hline & $A \times B$ & $F(1,18)=3.67, p=.07, \eta_{p}^{2}=.17$ \\
\hline & $A \times C$ & $F(1,18)=0.83, p=.37, \eta_{p}^{2}=.04$ \\
\hline & $\mathrm{B} \times \mathrm{C}$ & $F(1,18)=0.87, p=.36, \eta_{p}^{2}=.05$ \\
\hline & $A \times B \times C$ & $F(1,18)=0.51, p=.48, \eta_{p}^{2}=.03$ \\
\hline Go-N2 & A. Channels (Fz, FCz, Cz) & $F(2,36)=3.30, p<.05, \eta_{p}^{2}=.15$ \\
\hline \multirow[t]{6}{*}{ (220 - $320 \mathrm{~ms})$} & B. Present trial congruency & $F(1,18)=5.69, p<.05, \eta_{p}^{2}=.24$ \\
\hline & C. Previous trial congruency & $F(1,18)=0.89, p=.36, \eta_{p}^{2}=.05$ \\
\hline & $A \times B$ & $F(2,36)=6.48, p<.01, \eta_{p}^{2}=.26$ \\
\hline & $A \times C$ & $F(2,36)=2.39, p=.11, \eta_{p}^{2}=.12$ \\
\hline & $B \times C$ & $F(1,18)=0.87, p=.36, \eta_{p}^{2}=.05$ \\
\hline & $A \times B \times C$ & $F(2,36)=0.92, p=.41, \eta_{p}^{2}=.05$ \\
\hline Go-P3 & A. Channels (Pz, POz) & $F(1,18)=0.36, p=.56, \eta_{p}^{2}=.02$ \\
\hline \multirow[t]{6}{*}{ (300 - $400 \mathrm{~ms})$} & B. Present trial congruency & $F(1,18)=0.44, p=.52, \eta_{p}^{2}=.02$ \\
\hline & C. Previous trial congruency & $F(1,18)=1.97, p=.18, \eta_{p}^{2}=.10$ \\
\hline & $A \times B$ & $F(1,18)=0.17, p=.69, \eta_{p}^{2}=.01$ \\
\hline & $A \times C$ & $F(1,18)=0.13, p=.72, \eta_{p}^{2}=.01$ \\
\hline & $\mathrm{B} \times \mathrm{C}$ & $F(1,18)=0.00, p=.98, \eta_{p}^{2}=.00$ \\
\hline & $A \times B \times C$ & $F(1,18)=0.23, p=.64, \eta_{p}^{2}=.01$ \\
\hline Go-P3 & A. Channels (Pz, POz) & \\
\hline
\end{tabular}




\begin{tabular}{|ccc|} 
& $F(1,18)=0.46, p=.51, \eta_{p}{ }^{2}=.02$ \\
$(400-500 \mathrm{~ms})$ & B. Present trial congruency & $F(1,18)=14.47, p<.01, \eta_{p}^{2}=.45$ \\
& C. Previous trial congruency & $F(1,18)=3.98, p=.06, \eta_{p}^{2}=.18$ \\
$\mathrm{~A} \times \mathrm{B}$ & $F(1,18)=0.08, p=.77, \eta_{p}^{2}=.00$ \\
$\mathrm{~A} \times \mathrm{C}$ & $F(1,18)=0.00, p=.99, \eta_{p}^{2}=.00$ \\
$\mathrm{~B} \times \mathrm{C}$ & $F(1,18)=9.85, p<.01, \eta_{p}^{2}=.35$ \\
$\mathrm{~A} \times \mathrm{B} \times \mathrm{C}$ & $F(1,18)=0.46, p=.51, \eta_{p}{ }^{2}=.02$ \\
\hline
\end{tabular}

Table 3. Means (standard deviations) of event related potential amplitudes for Nogo-stimuli 


\begin{tabular}{|c|c|c|c|c|c|c|}
\hline & & $\mathrm{cC}$ & $\mathrm{iC}$ & $\mathrm{cl}$ & il & Main results $(a=.05)$ \\
\hline Nogo-N1 & P7 & -0.81 & -0.54 & -0.99 & -0.71 & $c>i$ \\
\hline \multirow[t]{3}{*}{$(150-200 \mathrm{~ms})$} & & $(1.65)$ & $(1.52)$ & $(1.62)$ & $(1.47)$ & \\
\hline & P8 & -0.56 & -0.65 & -0.72 & -0.53 & \\
\hline & & $(0.96)$ & $(0.92)$ & $(0.99)$ & $(1.12)$ & \\
\hline Nogo-N2 & $\mathrm{Fz}$ & -0.49 & -0.61 & -0.45 & -0.38 & $\mathrm{FC} z>\mathrm{C} z$ at $\mathrm{C}$ \\
\hline \multirow[t]{5}{*}{$(220-320 \mathrm{~ms})$} & & $(0.63)$ & $(0.71)$ & $(0.81)$ & $(0.82)$ & $\mathrm{iC}$ and $\mathrm{cl}>\mathrm{CC}$ at $\mathrm{FCz}$ \\
\hline & $\mathrm{FCz}$ & -0.49 & -0.80 & -0.90 & -0.71 & $\mathrm{cl}>\mathrm{il}$ and $\mathrm{iC}>\mathrm{cC}$ at $\mathrm{Cz}$ \\
\hline & & $(0.88)$ & $(0.76)$ & $(0.91)$ & $(0.88)$ & \\
\hline & $\mathrm{Cz}$ & 0.03 & -0.39 & -0.76 & -0.45 & \\
\hline & & $(1.08)$ & $(0.90)$ & $(0.66)$ & $(0.86)$ & \\
\hline Nogo-P3 & $\mathrm{FCz}$ & 0.76 & 0.61 & 1.07 & 1.07 & $\mathrm{FC} z$ and $\mathrm{Cz}>\mathrm{Pz}$ \\
\hline \multirow[t]{5}{*}{$(350-425 \mathrm{~ms})$} & & $(0.95)$ & $(0.91)$ & $(1.01)$ & $(1.13)$ & $C>1$ \\
\hline & $\mathrm{Cz}$ & 1.09 & 0.93 & 1.42 & 1.34 & $\mathrm{cl}>\mathrm{cC}, \mathrm{cl}>\mathrm{il}$ at $\mathrm{Pz}$ \\
\hline & & $(1.09)$ & $(1.15)$ & $(1.38)$ & $(1.29)$ & \\
\hline & $\mathrm{Pz}$ & 0.17 & 0.13 & 0.57 & 0.03 & \\
\hline & & $(0.81)$ & $(0.75)$ & $(0.76)$ & $(0.65)$ & \\
\hline Nogo-P3 & $\mathrm{FCz}$ & 0.11 & 0.08 & 0.70 & 0.36 & $\mathrm{I}>\mathrm{C}$ \\
\hline \multirow[t]{5}{*}{$(425-500 \mathrm{~ms})$} & & $(0.54)$ & $(0.68)$ & $(0.82)$ & $(0.69)$ & $\mathrm{cl}>\mathrm{il}>\mathrm{iC}$ and $\mathrm{cC}$ \\
\hline & $\mathrm{Cz}$ & 0.42 & 0.45 & 1.04 & 0.71 & \\
\hline & & $(0.86)$ & $(1.13)$ & $(1.26)$ & $(0.84)$ & \\
\hline & $\mathrm{Pz}$ & 0.20 & 0.24 & 0.53 & 0.20 & \\
\hline & & $(0.67)$ & $(0.65)$ & $(0.81)$ & $(0.77)$ & \\
\hline
\end{tabular}

Note. $\mathrm{cC}$ : congruent (the previous trial) $\rightarrow$ Congruent (the present trial), iC: incongruent $\rightarrow$ Congruent, cl: congruent $\rightarrow$ Incongruent, il: incongruent $\rightarrow$ Incongruent.

Table 4. Analyses of variance results of event related potential components for Nogo-stimuli 


\begin{tabular}{|c|c|c|}
\hline Components & Variable & Statistical value \\
\hline Nogo-N1 & A. Channels (P7,P8) & $F(1,18)=0.18, p=.68, \eta_{p}^{2}=.01$ \\
\hline \multirow[t]{6}{*}{$(150-200 \mathrm{~ms})$} & B. Present trial congruency & $F(1,18)=0.48, p=.50, \eta_{p}^{2}=.03$ \\
\hline & C. Previous trial congruency & $F(1,18)=11.45, p<.01, \eta_{p}^{2}=.39$ \\
\hline & $A \times B$ & $F(1,18)=0.37, p=.55, \eta_{p}^{2}=.02$ \\
\hline & $A \times C$ & $F(1,18)=2.60, p=.12, \eta_{p}^{2}=.13$ \\
\hline & $B \times C$ & $F(1,18)=1.66, p=.21, \eta_{p}^{2}=.08$ \\
\hline & $A \times B \times C$ & $F(1,18)=1.15, p=.30, \eta_{p}^{2}=.06$ \\
\hline Nogo-N2 & A. Channels (Fz, FCz, Cz) & $F(2,36)=1.76, p=.19, \eta_{p}^{2}=.09$ \\
\hline \multirow[t]{6}{*}{$(220-320 \mathrm{~ms})$} & B. Present trial congruency & $F(1,18)=2.59, p=.12, \eta_{p}^{2}=.12$ \\
\hline & C. Previous trial congruency & $F(1,18)=0.47, p=.50, \eta_{p}^{2}=.03$ \\
\hline & $A \times B$ & $F(2,36)=14.22, p<.001, \eta_{p}^{2}=.44$ \\
\hline & $A \times C$ & $F(2,36)=0.13, p=.88, \eta_{p}^{2}=.01$ \\
\hline & $B \times C$ & $F(1,18)=17.36, p<.001, \eta_{p}^{2}=.49$ \\
\hline & $A \times B \times C$ & $F(2,36)=7.69, p<.01, \eta_{p}^{2}=.30$ \\
\hline Nogo-P3 & A. Channels ( $\mathrm{FCz}, \mathrm{Cz})$ & $F(2,36)=7.62, p<.01, \eta_{p}^{2}=.30$ \\
\hline \multirow[t]{6}{*}{$(350-425 \mathrm{~ms})$} & B. Present trial congruency & $F(1,18)=20.06, p<.001, \eta_{p}^{2}=.53$ \\
\hline & C. Previous trial congruency & $F(1,18)=12.15, p<.01, \eta_{p}^{2}=.40$ \\
\hline & $A \times B$ & $F(2,36)=3.25, p=.05, \eta_{p}^{2}=.15$ \\
\hline & $A \times C$ & $F(2,36)=2.74, p=.08, \eta_{p}^{2}=.13$ \\
\hline & $B \times C$ & $F(1,18)=0.32, p=.58, \eta_{p}^{2}=.02$ \\
\hline & $A \times B \times C$ & $F(2,36)=4.18, p<.05, \eta_{p}^{2}=.19$ \\
\hline Nogo-P3 & A. Channels $(\mathrm{FCz}, \mathrm{Cz})$ & \\
\hline
\end{tabular}




\begin{tabular}{|ccc|} 
& & $F(2,36)=2.31, p=.11, \eta_{p}{ }^{2}=.11$ \\
$(425-500 \mathrm{~ms})$ & B. Present trial congruency & $F(1,18)=21.19, p<.001, \eta_{p}{ }^{2}=.54$ \\
& C. Previous trial congruency & $F(1,18)=5.54, p<.05, \eta_{p}{ }^{2}=.24$ \\
$\mathrm{~A} \times \mathrm{B}$ & $F(2,36)=2.50, p=.10, \eta_{p}^{2}=.12$ \\
$\mathrm{~A} \times \mathrm{C}$ & $F(2,36)=0.09, p=.90, \eta_{p}{ }^{2}=.01$ \\
$\mathrm{~B} \times \mathrm{C}$ & $F(1,18)=7.14, p<.05, \eta_{p}{ }^{2}=.28$ \\
$\mathrm{~A} \times \mathrm{B} \times \mathrm{C}$ & $F(2,36)=0.02, p=.98, \eta_{p}{ }^{2}=.00$ \\
\hline
\end{tabular}

\section{Figures}
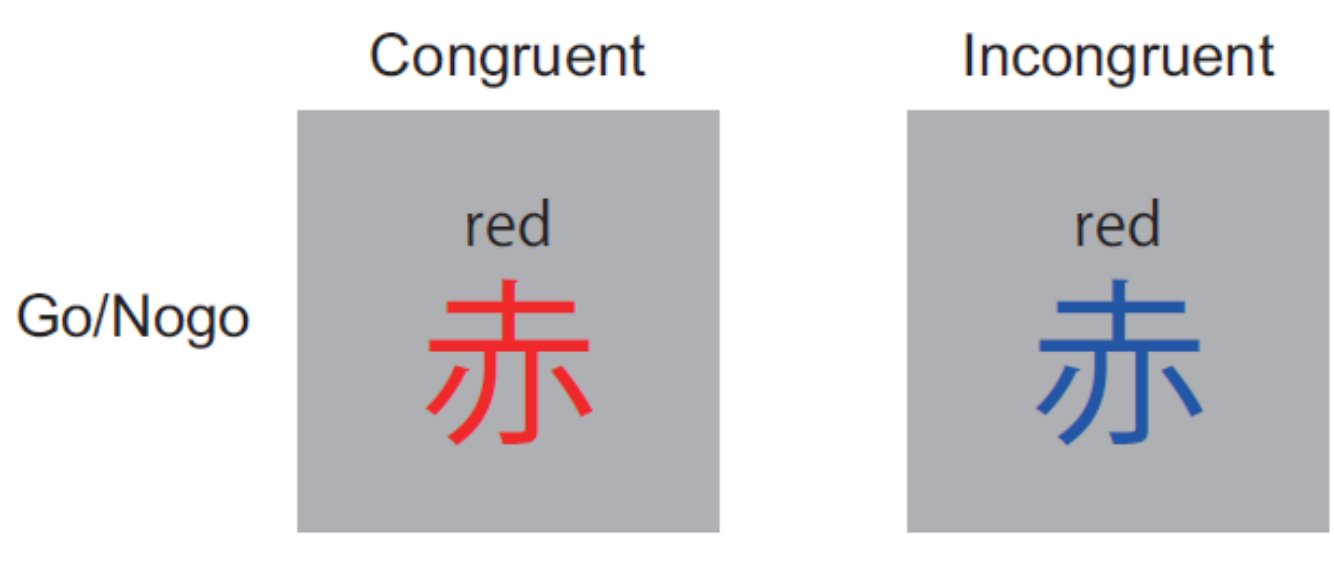

\section{Color task}

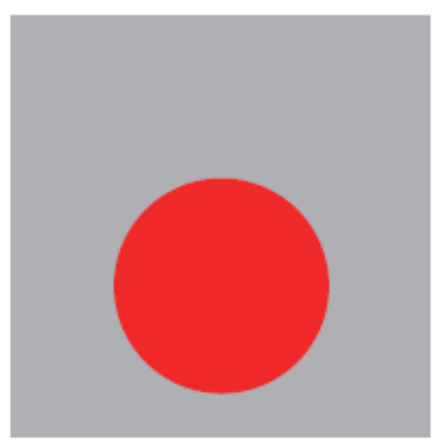

Nogo/Go
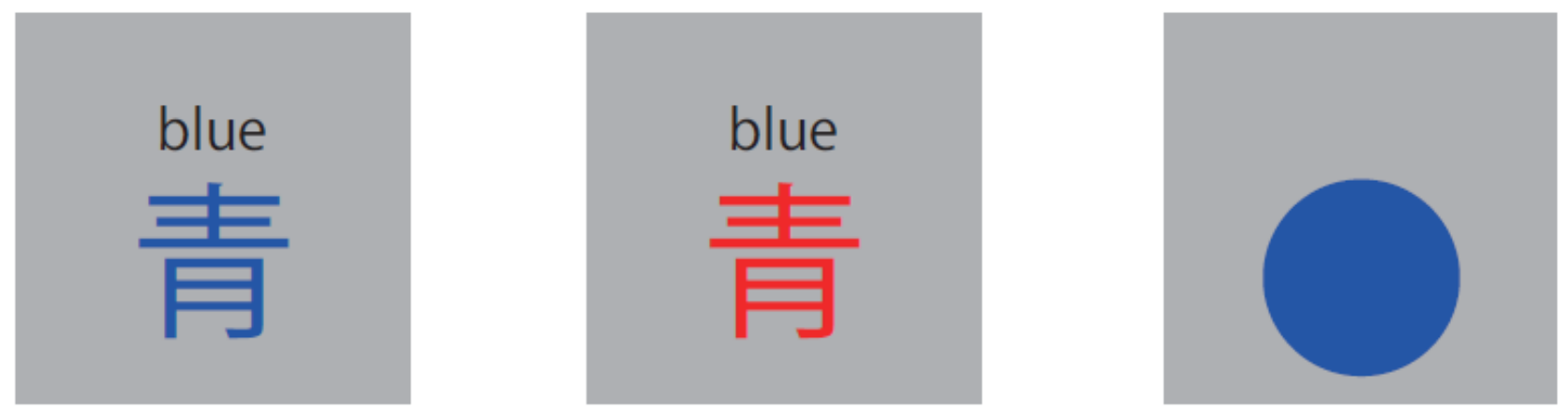

\section{Figure 1}

Tasks: “ $\square$ ” means "red," “ $\square$ " means "blue." Stimuli were presented for 100 ms with a stimulus onset asynchrony of $1200 \otimes 1500 \mathrm{~ms}$. 


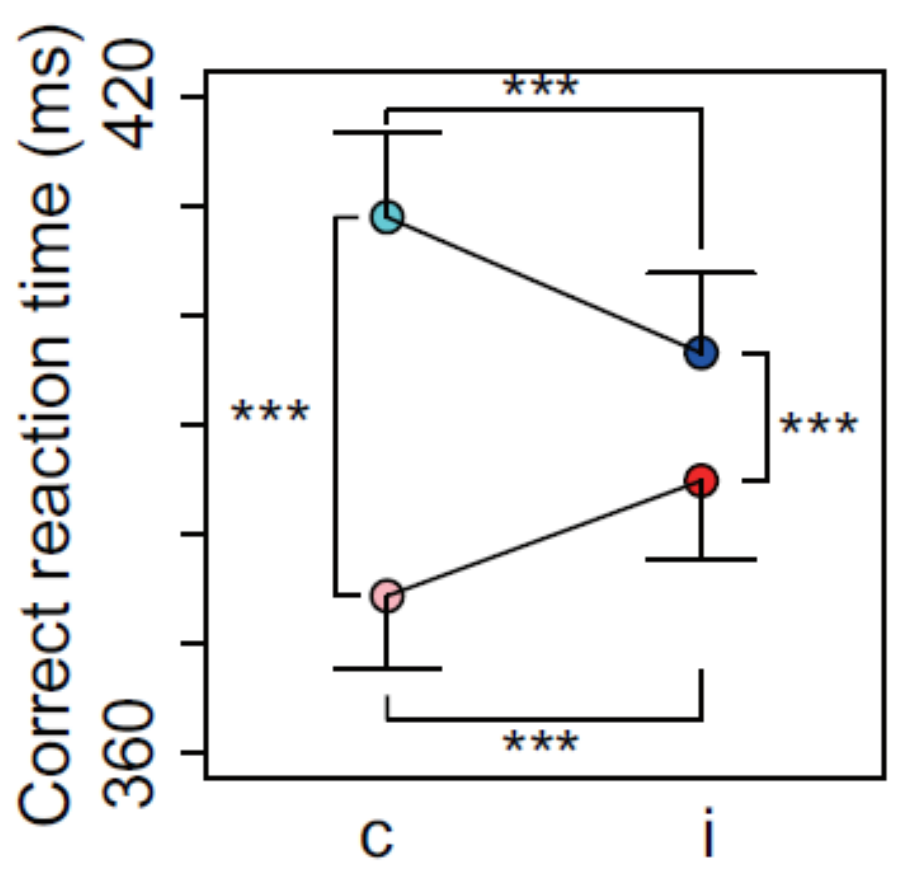

Previous trial congruency

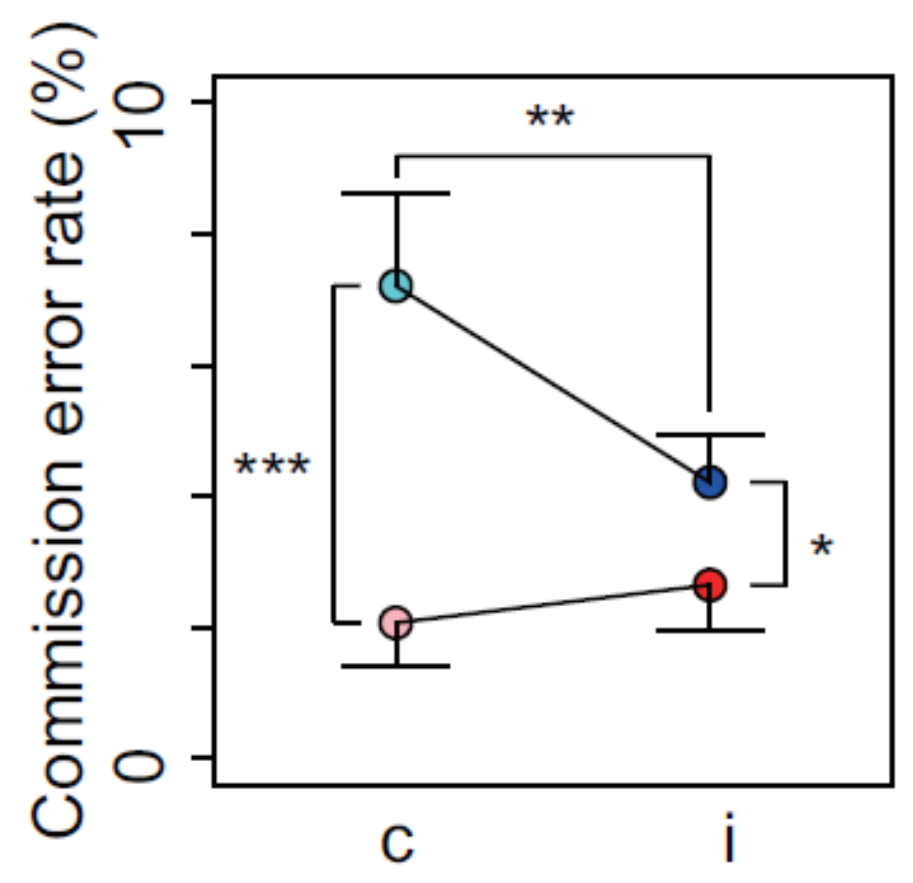

Previous trial congruency

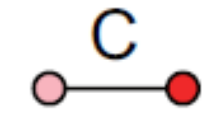

Present trial congruency
${ }^{*} p<.05,{ }^{* *} p<.01,{ }^{* * *} p<.001$

Figure 2

Behavioral results 

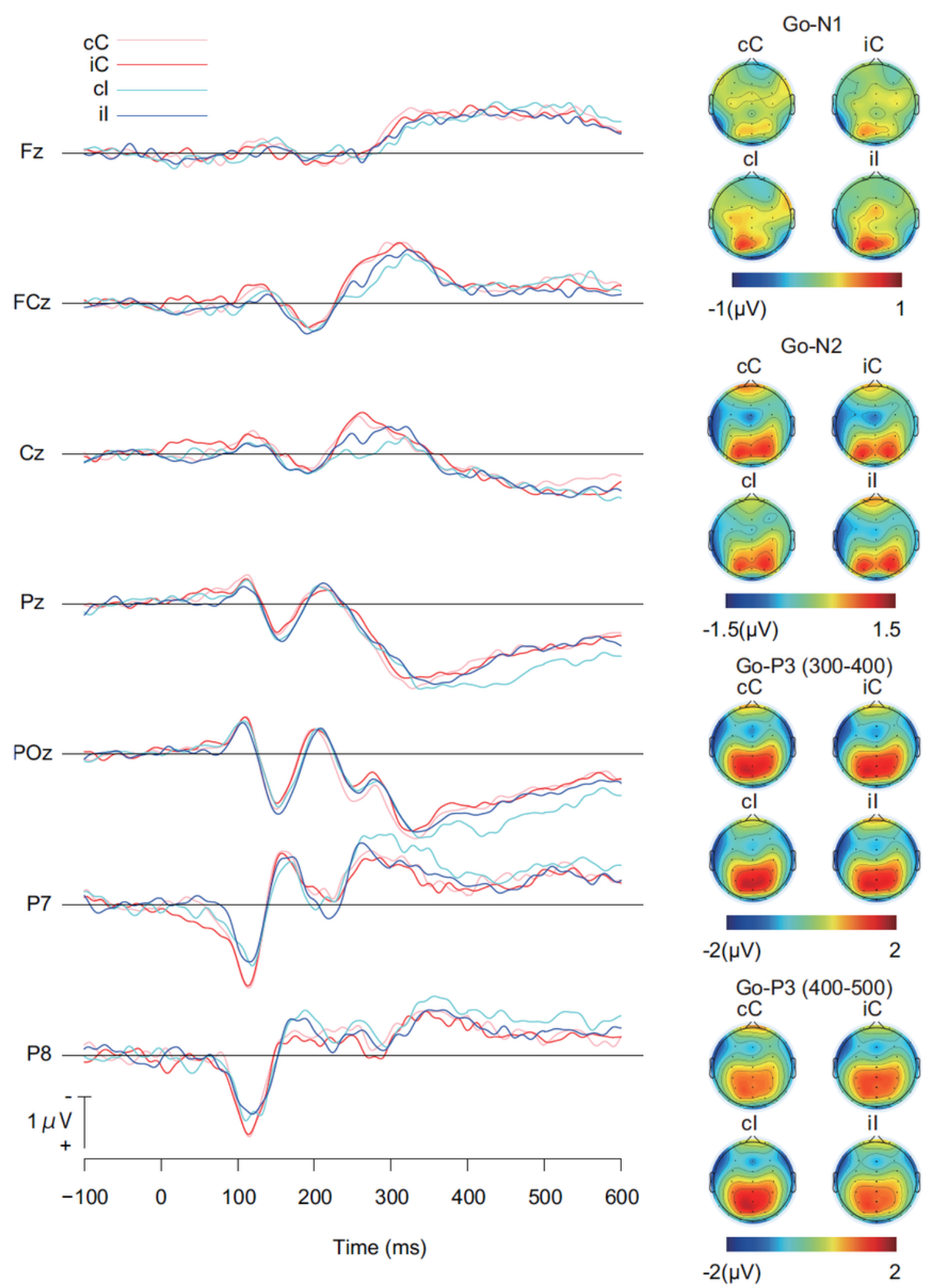

\section{Figure 3}

Grand average event related potential waveforms and topographies of Go-stimuli; congruent (the previous trial) $\rightarrow$ Congruent (the present trial), iC: incongruent $\rightarrow$ Congruent, cl: congruent $\rightarrow$ Incongruent, il: incongruent $\rightarrow$ Incongruent. 


\section{Go-P3 (400 - 500 ms)}

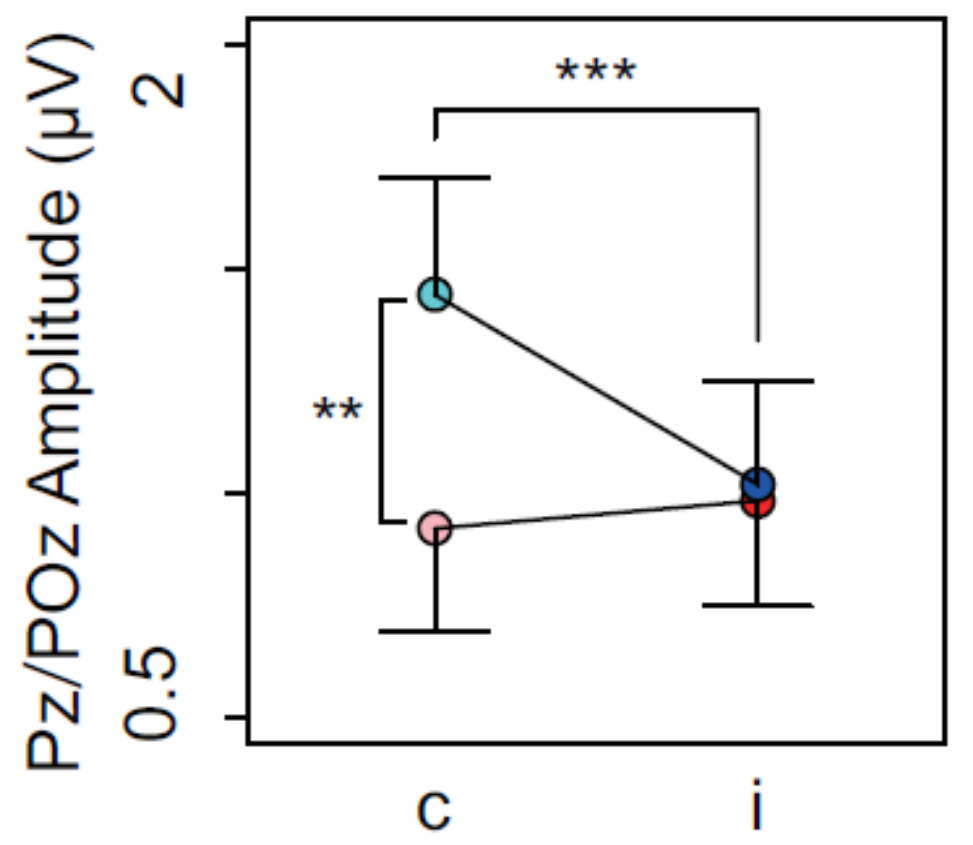

Previous trial congruency
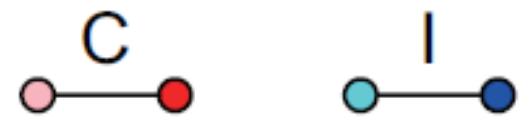

\section{Present trial congruency}

$$
{ }^{*} p<.05,{ }^{* *} p<.01,{ }^{* * *} p<.001
$$

Figure 4

Main results of event-related potential components for Go-stimuli; " $\mathrm{C}$ " and " $\mathrm{C}$ " represents congruent stimuli on previous and present trials, respectively. " $\mathrm{i}$ " and "I" represents incongruent stimuli on previous and present trials, respectively. 

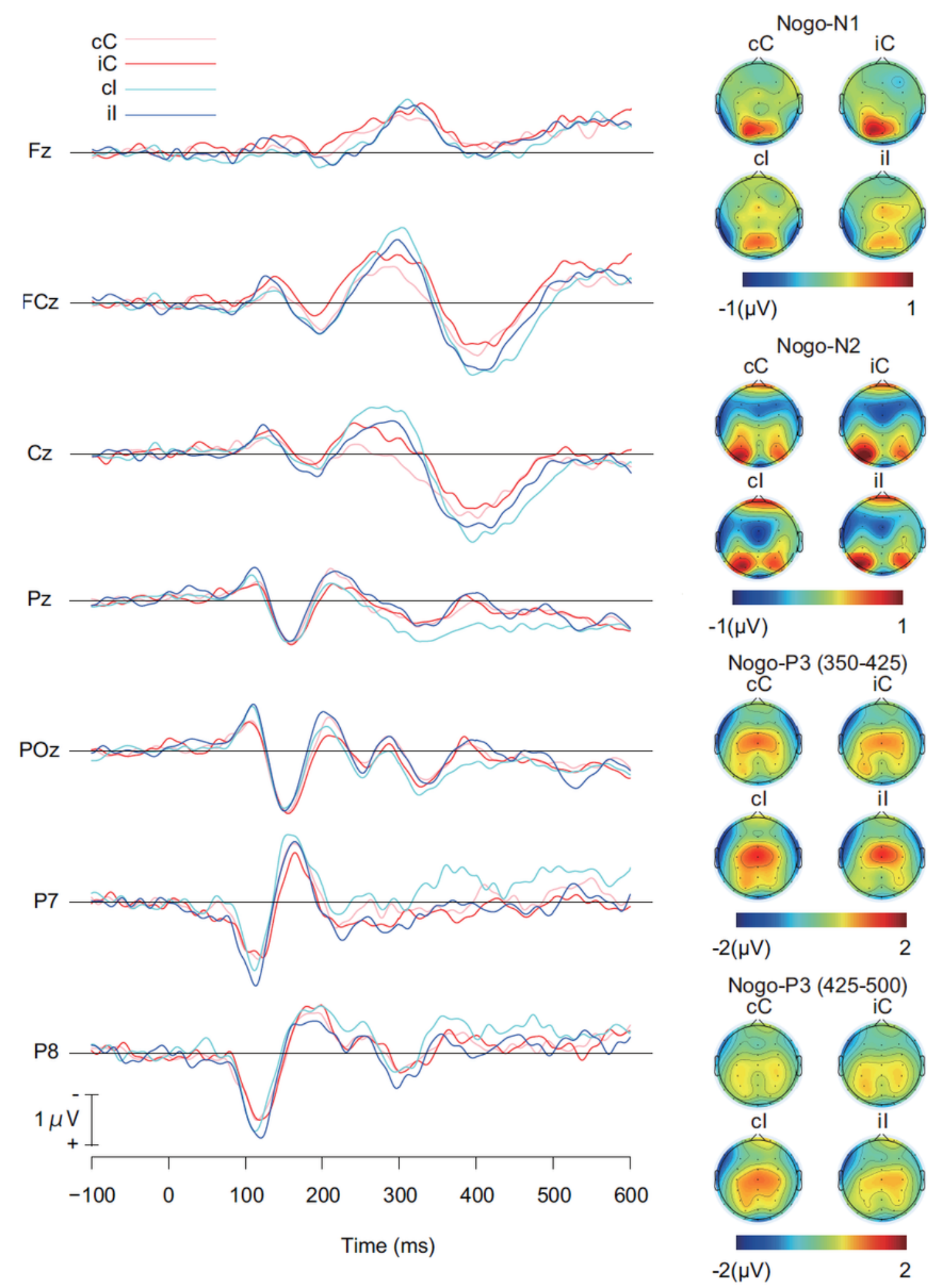

\section{Figure 5}

Grand average event related potential waveforms and topographies of Go-stimuli; congruent (the previous trial) $\rightarrow$ Congruent (the present trial), iC: incongruent $\rightarrow$ Congruent, cl: congruent $\rightarrow$ Incongruent, il: incongruent $\rightarrow$ Incongruent. 


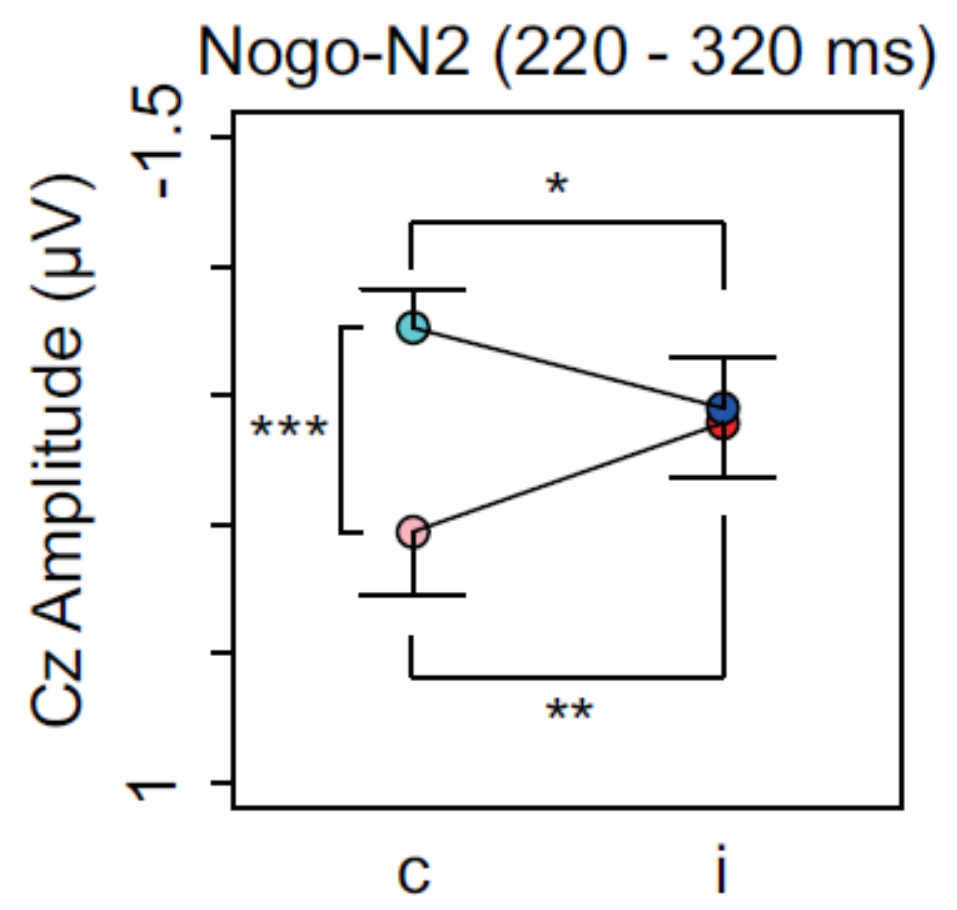

Previous trial congruency

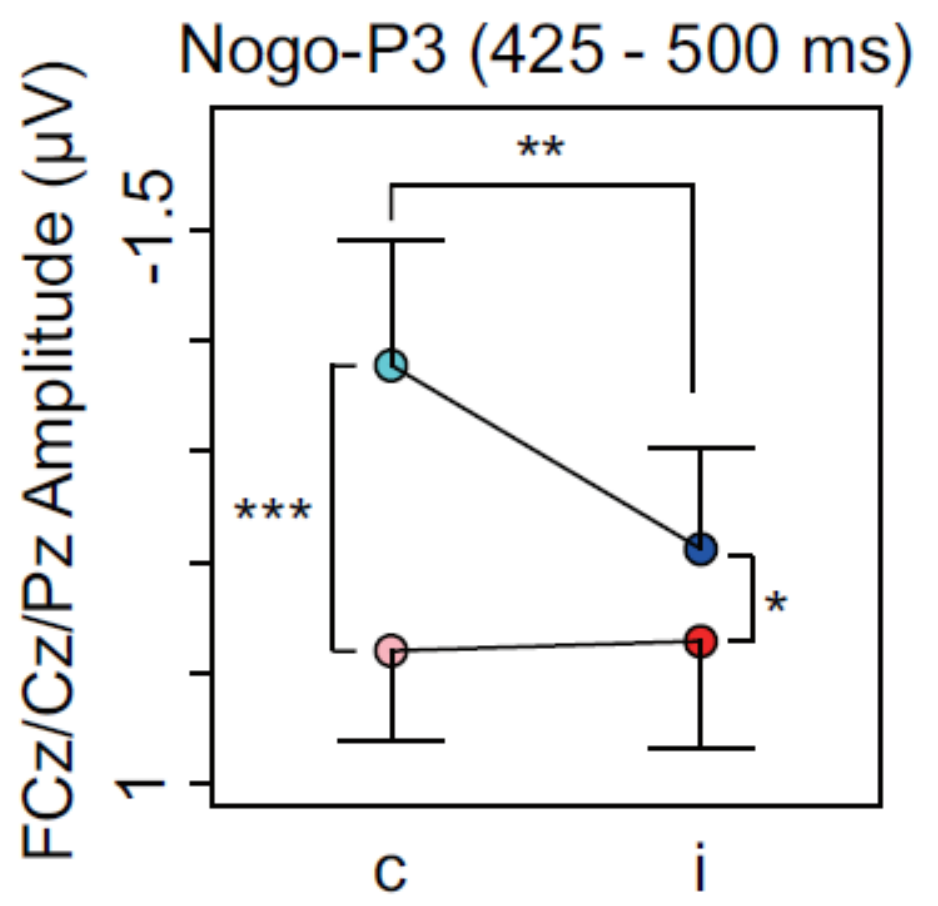

Previous trial congruency

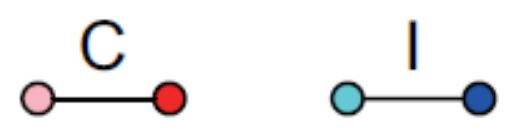

Present trial congruency ${ }^{*} p<.05,{ }^{* *} p<.01,{ }^{* *} p<.001$

Figure 6

Main results of event-related potential components for Nogo-stimuli; " $\mathrm{C}$ " and " $\mathrm{C}$ " represents congruent stimuli on previous and present trials, respectively. " $\mathrm{i}$ " and "I" represents incongruent stimuli on previous and present trials, respectively. 